\title{
Solitary "necrotic nodule" of the liver: a probable pathogenesis
}

\section{BERRY}

\section{From the Department of Morbid Anatomy, The London Hospital Medical College, London}

SUMMARY Examination of two lesions in the anterior margin of the liver suggested that the origin of the so called "solitary necrotic" nodule lies in non-malignant tissue. An origin in sclerosing haemagioma seems probable.

In 1983 Shepherd and Lee described five cases of an unusual lesion in the liver; four were described in detail and the other added as a note. ${ }^{1}$ The lesions were described as having a "completely necrotic core" and a hyalinised fibrotic capsule containing elastic fibres. The central areas of the cores contained reticulin in two cases, and an illustration of this suggested to me that the lesions might have originated in sclerosing haemangiomas.

The authors pointed out the importance of liver nodules to surgeons making exploratory investigations and emphasised the importance of an awareness of potentially confusing benign lesions that might be mistaken for metastases. Their differential diagnoses included several infectious processes, including visceral larva migrans, but sclerosing haemangioma was mentioned only in passing.

The two lesions described in this paper were dis-

Accepted for publication 9 July 1985 covered in a study of 1000 consecutive necropsies, in which the liver was cut in $1.5 \mathrm{~cm}$ slices along the saggital axis in an attempt to determine the incidence of benign lesions (CL Berry, data in preparation).

\section{CASE REPORTS}

Case 1 An 85 year old man was admitted to hospital with a diagnosis of cardiac failure. He died shortly after admission. He had had diabetes mellitus for 10 years, which had been controlled without insulin and he had had a prostatectomy 20 years before There was no other relevant history. At necropsy sacral and ankle oedema were found. He had died as a result of left ventricular failure due to calcific aortic stenosis with ischaemic heart disease. His liver showed a pattern of chronic venous congestion. Three cysts (all about $1.5 \mathrm{~cm}$ in diameter) were seen in the right lobe. Towards the anterior margin of the lobe a firm white lesion was seen (Fig. 1).

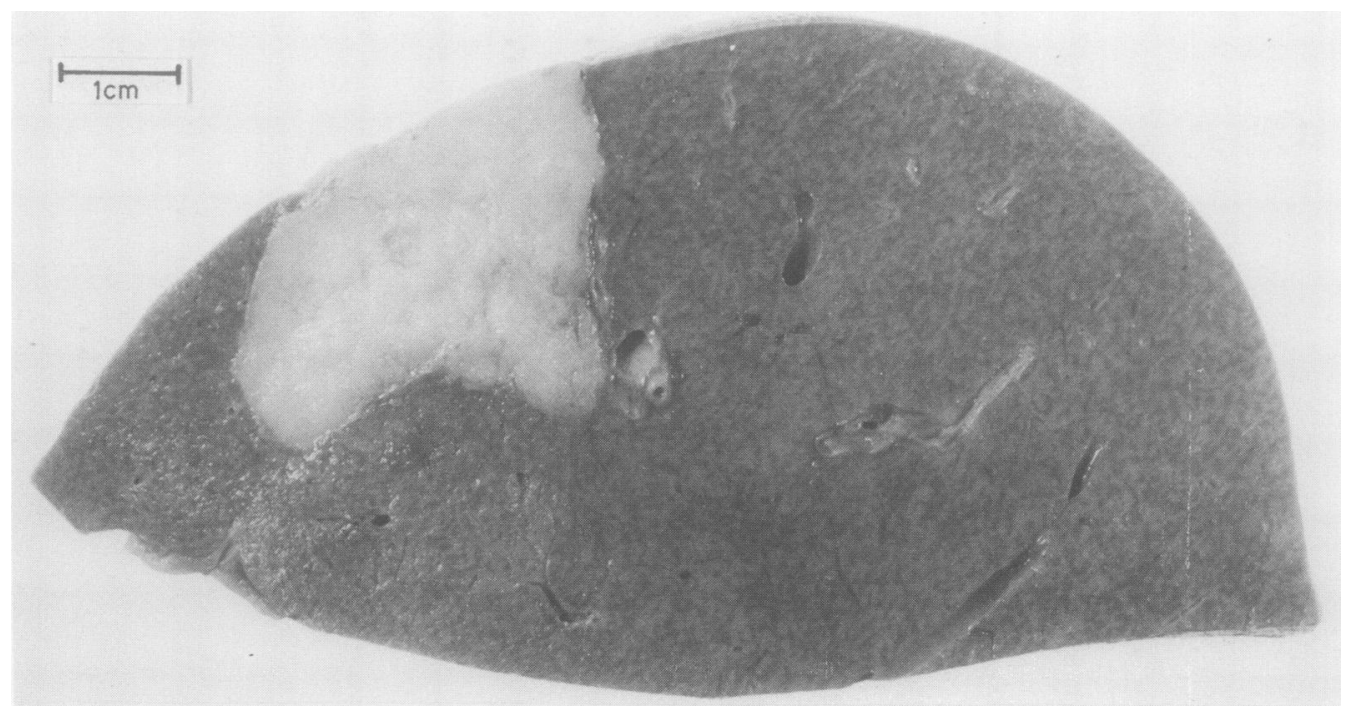

Fig. 1 Liver lesion in case 1. 


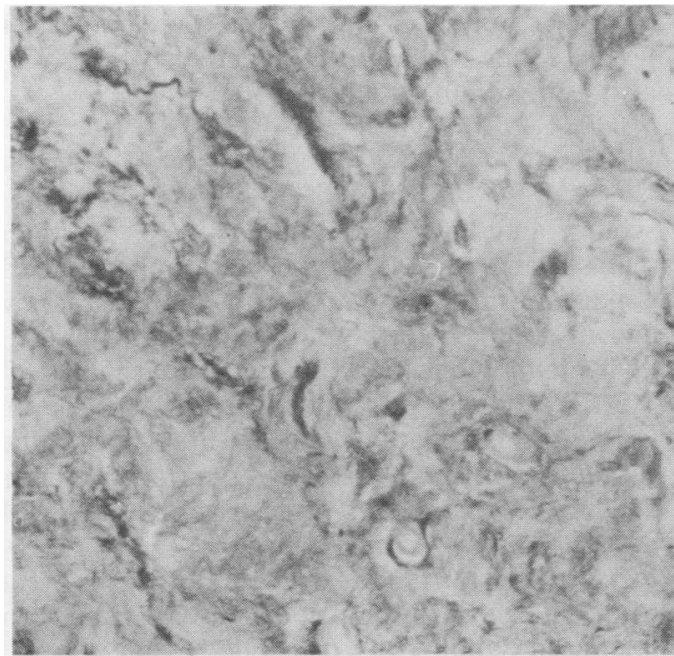

Fig. 2 Acellular area from case 1 (Elastic van Gieson.) $\times$ 150.

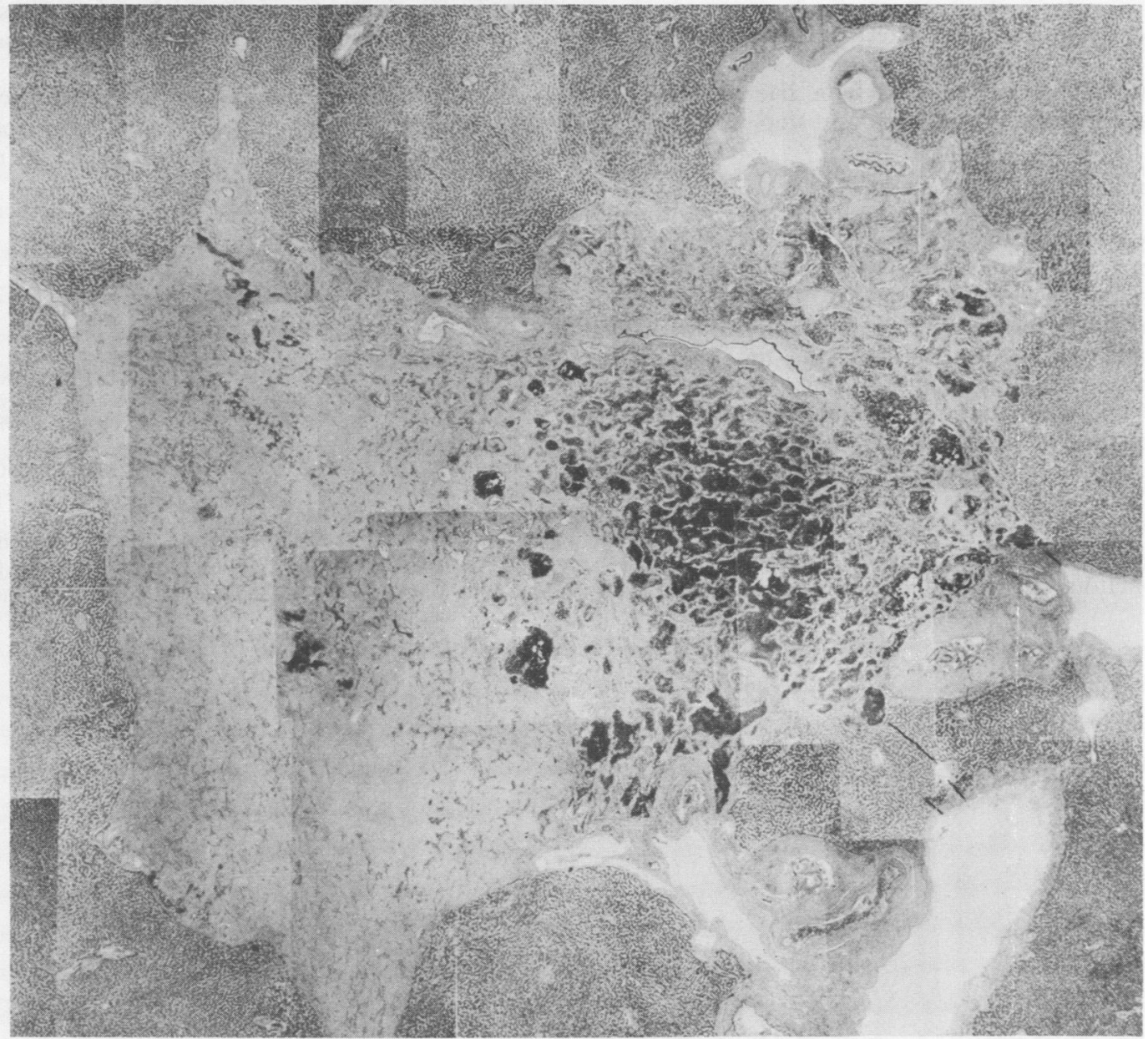

Fig. 3 Montoge of complete lesions in case 2, showing "feeder" vessels at lower part of frame, which fill a clearly haemangiomatous part of the lesion. Higher up the frame fewer vascular spaces and more sclerotic tissue, some of which is calcifying, can be seen. Predominant sclerosis in upper margin and other levels is evident. (Haematoxyliz and eosin.) $\times 12.5$. 
Case 2 A 76 year old man was admitted to hospital suffering from senile dementia. He developed bronchopneumonia after four weeks and died. Dementia had developed after a prostatectomy three years before admission. At necropsy a left nephrectomy scar was evident and the kidney was missing. This had been removed after a crushing injury in the second world war, during which he had worked as a fuel tank cleaner. There was severe bronchiectasis and bronchopnuemonia affecting both lower lobes, and the right ventricle was hypertrophied.

When the liver was cut a solitary lesion $1 \mathrm{~cm}$ in diameter was found in the right lobe, close to the anterior margin. The lesion was firm, and was white at its margins with a shading toward pink at one pole. It was clearly demarcated from surrounding liver cells.

\section{Material and methods}

The specimens were fixed in nominally buffered formalin, processed to paraffin, and sectioned at $5 \mu \mathrm{m}$. Thy were stained with haematoxylin and eosin and elastic van Gieson in step sections.

\section{Results}

\section{MICROSCOPY}

Case 1 The lesion was composed of acellular hyaline eosinophilic material that was essentially featureless. When several levels were examined occasional small vessels were seen in this apparently homogeneous material. Elastic stains showed some areas with a pattern resembling that of Fig. $1^{1}$ in the paper of Shepherd and Lee but most contained little elastic (Fig. 2). The pattern of collagen, however, appeared to outline vascular spaces when assessed at the margins and at several levels.

Case 2 "Feeder" vessels, filling a clearly haemangiomatous part of the lesion, were seen. The lesion contained four vascular spaces and more sclerotic tissue, some of which was calcifying. Sclerosis was also a predominant feature.

\section{Discussion}

Schultz and Hort, ${ }^{2}$ in a study of 11581 hepatic metastases, showed that $40 \%$ of lesions reached the hepatic surface and that in only $12 \%$ of cases were lesions confined to the deep aspects of the liver. A liver mantle $1 \mathrm{~cm}$ thick amounts to around $46 \%$ of the liver mass, and although only $40 \%$ of this is visible in the patient during life, ${ }^{3}$ the value to surgeons of inspecting the liver surface in the management of malignant disease is clear from these data.

Solitary lesions in the liver should not be assumed to be metastases if biopsy has not been performed. Shepherd and Lee concluded that they had identified a new source of potential confusion if such biopsies were not done and that the lesion had a distinct, if uncertain, pathogenesis.'

The lesions have features that resemble a "sclerosed" haemangioma, and it seems that the lesion in case 2 illustrates the way in which the lesion may evolve.

\section{References}

' Shepherd NA, Lee G. Solitary necrotic nodules of the liver simulating hepatic metastases. J Clin Pathol 1983;36:1181-3.

${ }^{2}$ Schultz W, Hort W. The distribution of metastases in the liver: a quantitative post mortem study. Virchows Arch $A$ 1981;394:89-96.

${ }^{3}$ McBride C. Das Lebermalignom. Temp Med 1979;2:25-30.

Requests for reprints to: Professor CL Berry, Department of Morbid Anatomy, The London Hospital Medical College, The London Hospital, London E1 1BB, England. 